\title{
Mesial temporal lobe epilepsy with hippocampal sclerosis
}

INSERM

\section{Source}

INSERM. (1999). Orphanet: an online rare disease and orphan drug data base. Mesial temporal lobe epilepsy with hippocampal sclerosis. ORPHA:99701

Mesial temporal lobe epilepsy with hippocampal sclerosis is a rare epilepsy syndrome defined by seizures originating in limbic areas of the mesial temporal lobe, particularly in the hippocampus, amygdala, and in the parahippocampal gyrus and its connections, and hippocampal sclerosis, usually unilateral or assymetric. It is frequently associated with an initial precipitating event, such as febrile seizures, hypoxia, intracranial infection or head trauma, most often occurring in the first five years of life, followed by a latent period without seizures. Typical seizures consist of a characteristic aura that is frequently a rising epigastric sensation associated with emotional disturbances, illusions, and autonomic symptoms (widened pupils, palpitations), progressive impairment of consciousness, oro-alimentary automatisms (lip smacking, chewing, licking, tooth grinding), behavioral arrest, head deviation, dystonic postures, hand and verbal automatisms. Seizures are followed by postictal dysfunction. Initially, seizures are easily controlled with antiepileptic drugs, later they frequently become refractory and associated with prog ressive behavioral changes and memory deficits. 